\title{
Comparison Using 2 Learning Model (Among Contextual and Numbered Head Cooperative Together NHT) Towards Student Learning Outcome in The High School (Case Study on Senior High School of SMA Negeri 5 Medan)
}

\section{Perbandingan Model Pembelajaran Kontekstual Dan Kooperatif Numbered Head Together (NHT) Terhadap Hasil Belajar Siswa (Studi kasus: SMA Negeri 5 Medan)}

\author{
Efrida Pima Sari Tambunan \\ Program Studi Biologi, Fakultas Sains dan Teknologi, Universitas Islam Negeri \\ Sumatera Utara, J1. IAIN No.1, Gaharu, Kecamatan Medan Timur, Kota Medan, \\ Sumatera Utara 20235 \\ *email: efrida_pima@uinsu.ac.id
}

Diterima 5 Agustus 2020 dan Disetujui 29 September 2020

\begin{abstract}
Abstrak
Penelitian ini bertujuan untuk memperoleh data empiris tentang perbandingan model pembelajaran kontekstual dengan model pembelajaran kooperatif tipe Numbered Head Together (NHT) terhadap hasil belajar siswa kelas X pada materi jamur di SMA Negeri 5 Medan. Tipe penelitian yang digunakan berupa penelitian tindakan kelas. Populasi dalam penelitian ini adalah siswa kelas X SMA Negeri 5 Medan yaitu 8 kelas. Teknik sampling diambil menggunakan metode random sampling pada 2 kelas. Pada kelas eksperimen pertama $\left(\mathrm{X}_{1}\right)$ diajarkan menggunakan model pembelajaran kontekstual dan kelas eksperimen kedua $\left(\mathrm{X}_{3}\right)$ menggunakan model pembelajaran kooperatif tipe $N H T$. Instrumen dalam pengumpulan data menggunakan test (tes hasil belajar). Validasi instrumen posttest diujicobakan pada kelas uji coba. Teknik analisis terkait validasi data diantaranya uji validasi, uji reliabilitas, uji daya beda soal dan uji taraf kesukaran soal untuk memilih pertanyaan yang dianggap baik untuk posttest. Pada kelas eksperimen pertama $\left(\mathrm{X}_{1}\right)$ diperoleh nilai rata-rata hasil belajar 7,2 dengan variansi 1,358 , sedangkan kelas $\left(\mathrm{X}_{3}\right)$ memperoleh nilai rata-rata hasil belajar 6,2 dengan variansi 1,102. Berdasarkan hasil analisis uji-t diperoleh bahwa ada perbandingan model pembelajaran kontekstual dengan model pembelajaran kooperatif tipe NHT terhadap hasil belajar siswa pada materi jamur kelas X di SMA Negeri 5 Medan

Kata Kunci: Model Pembelajaran, Pembelajaran Kontekstual, Pembelajaran Kooperatif tipe NHT

\section{Abstract}

This study aims to obtain empirical data regarding the comparison among contextual learning models and the Numbered Head Together (NHT) type of cooperative learning model on the $1^{\text {st }}$ grade class of learning outcomes on mushroom topics in the High School (on the SMA Negeri 5 Medan). The type of research was used classroom action research. The population in this study was grade first students of High School State 5 Medan, in a total of 8 classes. The sampling technique was taken using the random sampling method from 2 classes. The first-class experimental class $\left(X_{1}\right)$ was taught using a contextual learning model and the other class $\left(X_{3}\right)$ uses the NHT learning model. The data was collected using a test (test of learning outcomes). The validation instrument was tested out in the experimental class, then analyzed with the validation test, reliability test, discrimination power test and level of difficulty test to select questions that were considered good for the posttest. The first experimental class $\left(X_{1}\right)$ showed the average value of learning outcomes obtained was 7.2 with a variance of 1.358 , while the $\left(X_{3}\right)$ class obtained was an average value of 6.2 with a variance of 1.102 . Based on the results of the t-test analysis, it was found that there was a comparison of contextual learning models with NHT type cooperative learning models to student learning outcomes in class $X$ mushroom material at High School (SMA Negeri 5 Medan)
\end{abstract}


Keywords: Learning Model, Contextual Learning, Cooperative Learning, Numbered Head Together.

\section{PENDAHULUAN}

Pendidikan merupakan kebutuhan sepanjang hayat. Setiap orang membutuhkan pendidikan kapanpun dan dimanapun. Pendidikan sangat penting, karena tanpa pendidikan manusia akan sulit bahkan terbelakang. Oleh karena itu, pendidikan harus benar-benar diarahkan untuk menghasilkan sumber daya manusia (SDM) yang berkualitas dan mampu bersaing serta memiliki akhlak yang baik. Tanggung jawab profesional setiap guru untuk berusaha meningkatkan kualitas misi pendidikan. Guru memiliki tanggung jawab dan pengetahuan profesional yang memadai untuk membangun interaksi yang efektif dalam mencapai tujuan pembelajaran. Selain itu, guru harus dapat merangsang, membimbing siswa dan materi pembelajaran sesuai dengan tujuan untuk mendorong siswa mencapai hasil belajar yang terbaik. Melalui pembelajaran siswa harus mampu merangsang otak untuk berpikir dan kreatif dalam mengarahkan perubahan tingkah laku (Ardiyanti, 2018; Harahap, 2017).

Namun fakta di lapangan tidak sesuai harapan. Berdasarkan wawancara yang dilakukan dengan salah seorang guru biologi di SMA Negeri 5 Medan, salah satu faktor yang menyebabkan siswa kurang memahami materi biologi adalah metode, strategi, model pembelajaran dan teknik yang digunakan guru dalam pembelajaran biologi masih menggunakan model ceramah. Selain itu, mengajar menggunakan model ceramah berfokus hanya pada guru dan tidak melibatkan siswa dalam kegiatan belajar mengajar yang membuat siswa kurang mandiri, mengakibatkan kebosanan, dan membatasi kreativitas siswa.

Oleh karena itu, model pembelajaran kontekstual dan model pembelajaran kooperatif tipe NHT adalah salah satu model yang tepat untuk pembelajaran biologi. Mulyasa (2004) menginformasikan bahwa model pembelajaran kontekstual adalah model pembelajaran yang dapat membantu guru mengaitkan antara materi pembelajaran yang diajarkan dengan kehidupan nyata peserta didik, sehingga peserta didik dapat menghubungkan pengetahuan mereka dengan mengaplikasikan kehidupan sehari-hari. Hal yang berbeda dengan tipe model NHT, Nazliah (2017) menjelaskan bahwa model kooperatif tipe $N H T$ adalah salah satu tipe dari model kooperatif yang melibatkan lebih banyak peserta didik dalam menelaah materi yang tercakup dalam suatu pelajaran dan mengecek pemahaman mereka terhadap suatu mata pelajaran. Nazliah (2017); Huda (2016) menambahkan dalam mengaplikasikan model kooperatif tipe Numbered Heads Together (NHT) dapat berupa varian dari pola diskusi kelompok dimana, siswa dibagi dalam beberapa kelompok dan setiap anggota kelompok diberi nomor kepala untuk mendiskusikan masalah yang diberikan guru. Kemudian guru memanggil salah satu nomor dari satu kelompok untuk presentasi hasil diskusi dan tanggapan dari kelompok lain.

Langkah-langkah pembelajaran kontekstual menurut Johnson (2007) berupa: (a) Konstruktivisme adalah dasar dari pemikiran (filosofi) pembelajaran kontekstual, yaitu bahwa pengetahuan dibangun oleh manusia secara bertahap dan hasilnya diperluas dalam konteks terbatas. Pengetahuan bukanlah seperangkat fakta, konsep atau aturan 
yang diingat peserta didik tetapi pengetahuan harus dikontruksikan melalui pengalaman nyata; (b) Menemukan (inquiry) adalah proses pembelajaran berdasarkan pencarian dan penemuan melalui proses berpikir secara terstruktur. Nazliah \& Saragih (2019) menjelaskan secara umum, proses inquiry dapat dilakukan melalui beberapa langkah: pengamatan, penyelidikan, pengumpulan data, uji hipotesis berdasarkan data yang ditemukan dan menarik kesimpulan secara individu atau berkelompok; (c) Bertanya (questioning session) adalah strategi utama berdasarkan konteks dan dalam pembelajaran dipandang sebagai kegiatan guru yang bertujuan mendorong, membimbing, mengevaluasi kemampuan berpikir peserta didik, memotivasi belajar, serta rasa ingin tahu siswa dalam menemukan atau menarik kesimpulan; (d) Masyarakat belajar (learning community) mengimplikasikan bahwa hasil pembelajaran diperoleh melalui kerja sama dengan orang lain. Dalam kontekstual, guru disarankan untuk selalu mengajar dalam kelompok belajar yang heterogen; (e) Pemodelan (Modelling) adalah proses pembelajaran yang memperagakan beberapa contoh agar dapat ditiru oleh siswa. Model dapat dilakukan dengan mengoperasikan alat atau guru dapat memberikan contoh bagaimana melakukan sesuatu dengan memberikan model cara belajar. (f) Refleksi (Reflection) adalah cara berpikir tentang apa yang baru saja dipelajari atau apa yang telah dilakukan dimasa lalu. Di akhir pembelajaran, guru menyisakan sedikit waktu bagi siswa untuk berefleksi, sehingga dapat diimplementasikan dalam bentuk buku siswa dan diskusi, catatan, atau jurnal dalam buku dan karya siswa; (g) Penilaian Autentik (authentic assessment) adalah proses pengumpulan berbagai data dapat menguraikan perkembangan pembelajaran peserta didik. Dalam kontekstual, hal ini dapat digunakan sebagai dasar untuk mengevaluasi kinerja siswa dalam bentuk kuis, presentasi, laporan dan esai. Berdasarkan uraian permasalahan di atas, maka peneliti tertarik untuk melakukan penelitian mengenai perbandingan penggunaan 2 model pembelajaran antara kontekstual dan kooperatif Numbered Head Together (NHT) terhadap hasil belajar siswa di SMA Negeri 5 Medan.

\section{METODE PENELITIAN}

\section{Jenis \& Populasi Penelitian}

Penelitian ini merupakan penelitian eksperimen kuantitatif. Penelitian ini dilakukan di SMA Negeri 5 Medan pada semester genap T.A 2019/2020 selama 2 bulan. Variabel bebas adalah model pembelajaran kontekstual dan model pembelajaran kooperatif tipe $N H T$, variabel terikat adalah hasil belajar siswa. Populasi dalam penelitian ini adalah seluruh siswa kelas X SMA Negeri 5 Medan yang berjumlah 320 orang peserta didik.

\section{Prosedur \& Intrument Penelitian}

Pengambilan sampel penelitian ini menggunakan metode random sampling dengan sampel terpilih sebanyak 80 orang peserta didik. Pada kelas $\mathrm{X}_{1}$ diaplikasikan menggunakan model pembelajaran kontekstual dan kelas $\mathrm{X}_{3}$ diajar menggunakan model pembelajaran kooperatif tipe NHT. Instrumen penelitian berupa test dan dokumentasi. Instrument tes terdiri dari 25 soal yang berbentuk pilihan ganda. 
Langkah-Langkah Dalam Aplikasi Pembelajaran Kooperatif Learning Tipe NHT (Nazliah, 2017)

a. Langkah I, pemberian nomor (Numbering): pada tahap ini, guru membagi peserta didik menjadi berkelompok atau tim yang terdiri dari 3-5 orang dan setiap anggota kelompok diberi nomor 1-5.

b. Langkah II, mengajukan Pertanyaan (Questioning): guru bertanya kepada peserta didik. Pertanyaan dapat bervariasi dari spesifik ke umum.

c. Langkah III, berpikir Bersama (Head Together): Siswa berpikir Bersama untuk menyampaikan pendapat tentang jawaban atas pertanyaan dan menyakinkan bahwa setiap anggota kelompok atau tim mengetahui jawabannya.

d. Langkah IV, Pemberian jawaban (Answering): guru memanggil satu nomor dan masing-masing siswa dari tiap tim atau kelompok dengan nomor yang sama mengangkat tangan dan mencoba menjawab pertanyaan untuk seluruh kelas.

\section{Validasi Test}

Instrument tes yang terdiri dari 25 soal pilihan ganda selanjutnya dilakukan validasi dengan korelasi product moment, sehingga diperoleh 20 butir soal dinyatakan valid dan 5 butir soal dinyatakan tidak valid, uji reliabilitas tes dihitung KR-20 diperoleh koefisien reliabilitas sebesar 0,823 dengan kategori sedang diperoleh 17 butir soal, kategori sukar tidak ada kategori mudah diperoleh 3 butir soal. Daya pembeda didapatkan 2 butir soal kategori cukup, kategori baik 10 butir soal, dan 8 butir soal dikategorikan baik sekali.

\section{Teknik Analisa Data}

Pengujian hipotesis dalam penelitian ini menggunakan analisis parametrik dengan uji-t pada taraf signifikasi $5 \%(\alpha=0,05)$, dengan kriteria pengujian $\mathrm{H}_{0}$ ditolak dan menerima $\mathrm{Ha}$ jika $t_{\text {hitung }}>\mathrm{t}_{\text {tabel }}$ artinya ada perbandingan model pembelajaran kontekstual dengan model pembelajaran kooperatif tipe $N H T$ terhadap hasil belajar siswa kelas X pada materi jamur di SMA Negeri 5 Medan. Ha ditolak dan menerima $\mathrm{H}_{0}$ jika $\mathrm{t}_{\text {hitung }}<\mathrm{t}_{\text {tabel }}$ artinya tidak ada perbandingan model pembelajaran kontekstual dengan model pembelajaran kooperatif terhadap hasil belajar siswa kelas X pada materi jamur di SMA Negeri 5 Medan.

\section{HASIL DAN PEMBAHASAN Hasil}

Instrumen penelitian ini adalah lembar tes hasil belajar (post test) peserta didik. Sebelum diberikan kepada kelas eksperimen pertama yang diajarkan menggunakan model pembelajaran kontekstual yaitu kelas $\mathrm{X}_{1}$ dan kelas eksperimen kedua yang diajarkan menggunakan model pembelajaran kooperatif tipe NHT yaitu kelas $\mathrm{X}_{3}$. Pada Tabel 1 menunjukkan bahwa data hasil belajar eksperimen pertama $\mathrm{X}_{1}$ dengan jumlah siswa (N) 40 orang setelah mendapat perlakukan dengan model pembelajaran kontekstual memiliki nilai rata-rata 7,2 variansi 1,358. Sedangkan data hasil belajar eksperimen kedua $\mathrm{X}_{3}$ setelah mendapat perlakuan dengan model pembelajaran kooperatif tipe NHT memperoleh nilai rata-rata 6,2 variansi 1,102. Dari tabel 1. dapat dilihat terdapat selisih rata-rata post test sebesar 1 point. 
Setelah memberikan perlakuan, maka selanjutnya peserta didik diberikan soal post test. Hal ini digunakan untuk mengukur perbedaan hasil belajar setelah selesai pemberian perlakuan. Hasil nilai post test dapat dilihat pada gambar 1 .

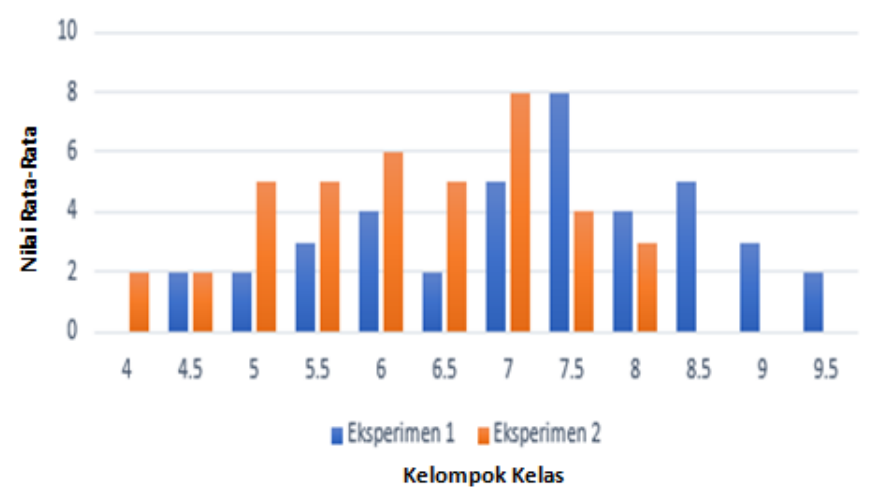

Gambar 1. Hasil Distribusi Frekuensi Nilai Posttest Kelas

Berdasarkan gambar 1. dapat diketahui bahwa hasil posttest di kelas eksperimen pertama $X_{1}$ memperoleh nilai terendah 4,5 dan nilai tertinggi 9,5. Pada kelas ekperimen kedua $\mathrm{X}_{3}$ memiliki nilai terendah 4 dan nilai tertinggi 8. Berdasarkan hasil perhitungan uji-t, maka diperoleh $t_{\text {hitung }}$ sebesar 3,610 dan $t_{\text {tabe }} 1$ sebesar 1,994 sehingga $t_{\text {hitung }}(3,610)>$ $t_{\text {tabel }}(1,994)$ sehingga $\mathrm{H} 0$ ditolak dan menerima Ha yang berarti ada perbandingan model pembelajaran kontekstual dengan model pembelajaran kooperatif tipe NHT terhadap hasil belajar siswa kelas X di SMA Negeri 5 Medan.

Tabel 1. Hasil Uji Statistik Deskriptif Post-test Hasil Belajar

\begin{tabular}{lcc}
\hline Statistik Deskriptif & $\begin{array}{c}\text { Kelas Ekperimen 1 } \\
\left(\mathbf{X}_{\mathbf{1}}\right)\end{array}$ & $\begin{array}{c}\text { Kelas Ekperimen 2 } \\
\left(\mathbf{X}_{\mathbf{3}}\right)\end{array}$ \\
\hline $\mathrm{N}$ & 40 & 40 \\
Nilai Tertinggi & 9,5 & 8 \\
Nilai Terendah & 4,5 & 4 \\
Mean & 7,2 & 6,2 \\
Variansi & 1,358 & 1,102 \\
\hline
\end{tabular}

\section{Pembahasan}

Pengajaran dengan menggunakan model pembelajaran kooperatif tipe NHT merupakan jenis pembelajaran kooperatif yang mempengaruhi pola interaksi peserta didik dalam menelaah materi pembelajaran dengan cara seperti memberi penomoran, mengajukan pertanyaan, serta berpikir bersama dan menjawab pertanyaan, dapat memotivasi siswa untuk lebih aktif dan kreatif dalam bertanya maupun memberikan pendapat dalam proses pembelajaran berlangsung. Johnson (2007) menambahkan model pembelajaran kontekstual memiliki keuntungan seperti konsep abstrak dapat yang lebih mudah dipahami oleh siswa karena media yang digunakan secara langsung atau nyata, peserta didik lebih aktif dalam mengikuti pembelajaran dengan memberikan pertanyaan serta tanggapan dan merefleksikan hasil pembelajaran serta mengembangkan rasa ingin tahu peserta didik dan mempelajari konsep atau materi pelajaran secara mendalam. Hal 
ini disebabkan karena memiliki kelemahan seperti yang dikemukakan oleh Slavin dalam Huda (2011) bahwa guru harus mempersiapkan pelajaran dan juga membutuhkan ide, waktu dan lebih banyak tenaga; agar proses pembelajaran berjalan dengan lancer diperlukan fasilitas, alat dan anggaran yang memadai; dalam kegiatan diskusi kelompok ada kecenderungan bahwa topik masalah yang sedang dibahas meluas, sehingga banyak orang tidak beradaptasi dengan waktu yang ditentukan; dalam diskusi kelas terkadang didominasi oleh seseorang yang membuat peserta didik lainnya menjadi pasif.

\section{KESIMPULAN}

Berdasarkan uraian hasil penelitian diatas dapat disimpulkan pembelajaran menggunakan model kontekstual lebih baik ketimbang model pembelajaran kooperatif tipe NHT dimana nilai rata-rata hasil belajar peserta didik yang diajar menggunakan model kontekstual sebesar 7,2 dengan variansi 1,358. Sedangkan nilai rata-rata hasil belajar peserta didik yang diberikan pengajaran menggunakan model pembelajaran kooperatif sebesar 6,2 dengan variansi 1,102. Dari uji hipotesis $t_{\text {hitung }}>t_{\text {tabel }}$ yaitu $(3,610)$ $>(1,994)$, sehingga hipotesis nihil (H0) ditolak dan menerima hipotesis alternatif ( $\mathrm{Ha})$ yang artinya ada perbandingan model pembelajaran kontekstual dengan model pembelajaran kooperatif tipe $N H T$ terhadap hasil belajar siswa kelas X di SMA Negeri 5 Medan.

\section{DAFTAR PUSTAKA}

Ardiyanti, T. 2018. Peningkatan Hasil Belajar Siswa Kelas V Mata Pelajaran IPA Menggunakan Model Pembelajaran Kooperatif Tipe NHT (Numbered Head Together). Jurnal Publikasi Pendidikan. Volume 8(2): 24-31

Arikunto, S. 2012. Penelitian Tindakan Kelas. Jakarta: Bumi Aksara

Arikunto, S. 2017. Dasar-dasar Evaluasi Pendidikan Edisi 2. Jakarta: PT Bumi Aksara.

Firdaus, M. 2016. Penerapan Model Pembelajaran Kooperatif Tipe Numbered Head Together (NHT) Ditinjau Dari Aktivitas Belajar Siswa Kelas VIII SMP. Jurnal Formatif. Volume 6(2): 93-99.

Harahap, R.D. 2015. Pengaruh Model Problem Based Learning Terhadap Hasil Belajar Siswa Pada Materi Pokok Perkembangan Manusia Kelas VIII SMP Negeri 4 Kualuh Selatan Kabupaten Labuhanbatu Utara. Jurnal Pembelajaran dan Biologi Nukleus. Volume 1(1): 14-17.

Huda, M. 2016. Cooperatif Learning. Yogyakarta: Pustaka Pelajar.

Johnson, E.B. 2007. Contextual Teaching and Learning: Menjadikan Kegiatan Belajar Mengajar Mengasyikkan dan Bermakna. Bandung: Mizan Learning Center (MLC).

Komalasari, K. 2017. Pembelajaran Kontekstual Konsep dan Aplikasi. Bandung: Refika Aditama. 
Lie, A. 2010. Cooperative Learning Mempraktikkan Cooperative Learning di Ruang-Ruang kelas. Jakarta: Grasindo.

Mulyasa, E. 2004. Implementasi Kurikulum 2004. Bandung: Remadja Karya.

Nazliah, R. 2017. Pengaruh Penggunaan Model Pembelajaran Kooperatif NHT (Numbered Head Together) Dalam Meningkatkan Hasil Belajar Siswa Pada Sub Materi Pokok Sistem Reproduksi Pada Manusia Di Kelas XI IPA SMA Negeri 1 Kualuh Hulu Aek Kanopan. Jurnal Pembelajaran dan Biologi Nukleus. Volume 3(1): 42-46.

Nazliah, R., Saragih S.Z. 2019. Pengaruh Model Pembelajaran Inquiry Terhadap Hasil Belajar Pada Materi Pencemaran Lingkungan Di SMA Negeri 1 Kualuh Bulu. Jurnal Pembelajaran dan Biologi Nukleus. Volume 5(2): 49-53.

Sardiman. 2011. Interaksi dan Motivasi Belajar Mengajar. Jakarta: PT. Raja Grafindo Persada.

Sugiyono. 2017. Statistik untuk Penelitian. Bandung: Alfabeta.

Trianto. 2015. Mendesain Model Pembelajaran Inovatif, Progresif, Dan Kontekstual. Jakarta: Kencana. 